Article

\title{
Solid State Stability and Preformulation Studies for Acetylcholinesterase Inhibitor Drug Tacrine
}

\author{
Denisa Circioban $^{1,2}$, Ionuț Ledeți ${ }^{1,2, *}$, Gabriela Vlase ${ }^{3}$, Titus Vlase ${ }^{3}$ and \\ Adriana Ledeți ${ }^{1,2}$ \\ ${ }^{\text {I }}$ First Department of Pharmacy, Faculty of Pharmacy, "Victor Babeş” University of Medicine and Pharmacy, \\ 2 Eftimie Murgu Square, 30004I Timişoara, Romania; circioban.denisa@umft.ro (D.C.); afulias@umft.ro (A.L.) \\ ${ }^{2}$ Advanced Instrumental Screening Center, Faculty of Pharmacy, "Victor Babes” University of Medicine and \\ Pharmacy Timisoara, Romania, 2 Eftimie Murgu Square, 30004I Timişoara, Romania \\ ${ }^{3}$ Research Centre for Thermal Analysis in Environmental Problems, West University of Timisoara, i6 Pestalozzi Str., \\ 30oIs Timişoara, Romania; gabriela.vlase@e-uvt.ro (G.V.); titus.vlase@e-uvt.ro (T.V.) \\ *Correspondence: ionut.ledeti@umft.ro; Tel.: +40-256-494-604
}

Submitted: I8 September 2020; Accepted: I4 October 2020; Published: 2I October 2020

\begin{abstract}
In this paper, the acetylcholinesterase inhibitor drug tacrine was investigated by two complementary instrumental techniques, namely infrared spectroscopy and thermal analysis, as pure drug and in solid binary mixtures with nine excipients frequently used in the pharmaceutical industry, namely starch, sodium carboxymethyl cellulose, polyvinylpyrrolidone $\mathrm{K}_{3} \mathrm{O}$, fumed silica (Aerosil), talc, anhydrous lactose, magnesium stearate, mannitol and calcium lactate pentahydrate. The corroboration of obtained data by the two complementary methods confirmed the incompatibility of this drug with anhydrous lactose, mannitol, magnesium stearate and calcium lactate under both ambient conditions and thermal stress, and thermally induced interactions between tacrine and silica. In the development of new generic solid formulations, four of the investigated excipients (i.e., starch, sodium carboxymethyl cellulose, polyvinylpyrrolidone $\mathrm{K}_{3} \mathrm{O}$ and talc) can be used, since they are compatible with tacrine under ambient conditions as well as under thermal stress.
\end{abstract}

Keywords: instrumental investigation; thermal analysis; FTIR; tacrine; Acetylcholinesterase Inhibitor

How to cite: Circioban, D.; Ledeți, I.; Vlase, G.; Vlase, V.; Ledeți, A. Solid State Stability and Preformulation Studies for Acetylcholinesterase Inhibitor Drug Tacrine. Timisoara Med. 2020, 2020(I), 4; doi:10.35995/tmj20200104.

\section{Introduction}

Alzheimer's disease $(\mathrm{AD})$ or Alzheimer's dementia was first characterized at the beginning of the 20 th century by Dr. Alois Alzheimer. The progressive neurodegenerative disorder is an incurable disease that affects almost 25 million people worldwide, according to the World Health Organization provided data [I]. The most common symptoms associated with this disease include progressive memory loss, disorientation, personality and mood changes, struggles while performing daily tasks, communication problems, poor judgement, sleep disturbances and difficulty recognizing family or friends. However, as the disease progresses, more severe 
symptoms arise, such as loss of appetite, trouble swallowing, considerable weight loss, severe memory loss and loss of bladder and bowel control, all of which lead to a total dependence of the patient on a caregiver [2].

There are many hypotheses currently being researched to determine the factors involved in the onset of the disease. Among these, the literature mentions the reduction in acetylcholine (ACh) synthesis as the primary cause, since it was clinically observed that patients suffering from $\mathrm{AD}$ present with deterioration of cholinergic neurons and loss of neurotransmission that, in turn, lead to declined cognitive function. Since one of the potential therapeutic strategies is focused on the increase in ACh levels, the utilized medication is meant to reduce the degradation of ACh by inhibiting its enzymatic degradation catalyzed by acetylcholinesterase (AChE). Thus, the pharmaceutical class of AChE inhibitors was developed [3].

Tacrine or tetrahydroaminoacridine is a reversible, competitive AChE inhibitor, the first representative of its class to receive the approval of Food and Drug Administration (FDA) for the treatment of AD. Its synthesis and initial characterization dates back to 1945, when Adrien Albert and Walter Gledhill from the University of Sydney obtained the compound while searching for an antiseptic to be used on the soldiers fighting in World War 2. However, the first mention of tacrine in the Pharmacopoeia was not made until $1963[4,5]$.

Tacrine (IUPAC name: 1,2,3,4-tetrahydroacridin-9-amine) is a solid with a melting point of $183.5^{\circ} \mathrm{C}$ and a molar mass equal to $198.27 \mathrm{~g} \cdot \mathrm{mol}^{-1}$. Its water solubility at room temperature is $217 \mathrm{mg} \cdot \mathrm{L}^{-1}$ [6]. To improve its solubility, it is usually formulated as hydrochloride. Monohydrated TCR hydrochloride is a white solid, freely soluble in water, aqueous buffers, ethanol and dimethylsulfoxide (DMSO), that melts at around $283-286{ }^{\circ} \mathrm{C}[7]$. The structural formula of tacrine hydrochloride hydrate (TCR) is shown in Figure I.

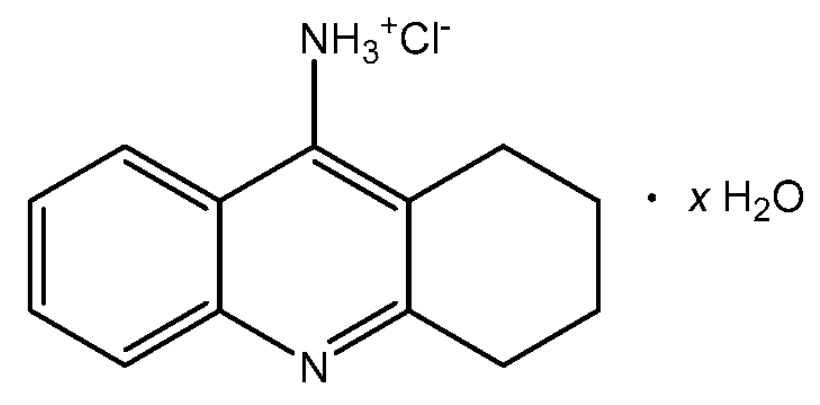

Figure 1. Structural formula of tacrine hydrochloride hydrate (TCR).

After oral administration, TCR is well absorbed at a gastrointestinal level, due to its lipophilic properties. Significant interindividual differences were observed regarding the time required to reach the maximum plasmatic concentration, with this varying between 0.5 and 3 hours. Due to an intense first-pass hepatic metabolism, TCR's oral bioavailability is low, approximately $17 \%$. Its elimination is conducted through the urinary tract, after a quick and extensive hepatic metabolization [8].

Despite its effectiveness in the palliative treatment protocols of mild and moderate forms of $\mathrm{AD}$, clinical trials have revealed a series of side effects associated with the use of TCR, such as nausea, vomiting, abdominal pain, diarrhea, loss of appetite, myalgia or dizziness [9]. However, the most severe reported effect is high liver toxicity and, as such, TCR is currently administered under constant monitoring, with its use even being forbidden in some countries [3,Io]. Because of these aspects, current pharmaceutical research is focused on either the development of new derivatives or the modification of the existing formulations so as to overcome these disadvantages [II-I4]. 
In order to design and manufacture a pharmaceutical formulation, not only the physico-chemical profile of the active pharmaceutical ingredient (API) needs to be completely understood, but also its possible interactions with the used excipients. Each of these compounds have different roles in a pharmaceutical formulation, but they all have to adhere to a few key regulations, such as lack of toxicity, thermal and chemical stability and lack of physical or chemical interactions with the active compounds. The last requirement is most commonly studied during the preformulation stages of the drug manufacturing process, using a series of instrumental techniques [15-17].

Therefore, the aim of the present study was a stability evaluation of and potential interaction determination between TCR, a pharmacologically active compound, and nine different excipients frequently used in the pharmaceutical industry, namely starch, sodium carboxymethyl cellulose, polyvinylpyrrolidone $\mathrm{K}_{3} \mathrm{O}$, fumed silica (Aerosil), talc, anhydrous lactose, magnesium stearate, mannitol and calcium lactate pentahydrate. As part of the study, two instrumental techniques were employed, UATR-FTIR spectroscopy and thermal analysis (TG/DTG/HF).

\section{Materials and Methods}

The active pharmaceutical ingredient (Tacrine, abbreviated TCR) was purchased as hydrate hydrochloride salt, from Sigma-Aldrich, Darmstadt, Germany (purity $\geq 99 \%$, molecular weight $234.72 \mathrm{~g} / \mathrm{mol}$ for anhydrous basis, CAS Number: 206658-92-6). The selected excipients were of pharmaceutical grade, suitable for use in solid formulations: calcium lactate (CaL, Aldrich, Steinheim, Germany), mannitol (Man, Merck, Darmstadt, Germany), magnesium stearate (MgSt, Union Derivan, Barcelona, Spain), anhydrous lactose (LAnh, Merck, Darmstadt, Germany), talc (T, Luzenac Pharma, Porte, Italy), fumed silica $\left(\mathrm{SiO}_{2}\right.$, Aerosil 2oo, Evonik Degussa, Essen, Germany), polyvinylpyrrolidone $\mathrm{K}_{30}$ (PVP, Sigma-Aldrich, Steinheim, Germany), sodium carboxymethyl cellulose (NaCMC, Sigma-Aldrich, Steinheim, Germany) and starch (St, Grain Processing Corporation, Muscatine, IA, USA).

The heterogenous binary mixtures prepared between TCR and each selected excipient consisted of equal masses of pure reagents that were triturated in an agate mortar with pestle for approximately $5 \mathrm{~min}$, then sieved and transferred in sealed vials. After preparation, the vials were kept at $22 \pm 2{ }^{\circ} \mathrm{C}$ in a desiccator, away from light. The I:I mass ratio was chosen in order to emphasize the occurring interactions between the reactive functional groups of TCR and each excipient.

As instrumental screening techniques of the samples, two complementary methods were implemented, namely Universal Attenuated Total Reflection Fourier Transform Infrared Spectroscopy (UATR-FTIR) and thermal analysis (TG-thermogravimetry/DTG-derivative thermogravimetry/HF-heat flow curves, simultaneously recorded during advance of thermal treatment). UATR-FTIR spectra were recorded using a Perkin Elmer SPECTRUM Ioo instrument. Spectra were collected in the $4000-650 \mathrm{~cm}^{-1}$ spectral range, with a resolution of $\mathrm{I} \mathrm{cm}^{-1}$ and with $64 \mathrm{co}$-added scans. The samples were investigated as prepared, without further treatment. The bands observed between 2400 and $1900 \mathrm{~cm}^{-1}$ have no spectroscopic significance, since they represent the noise signal of the UATR crystal.

The thermoanalytical curves TG/DTG/HF were recorded in dynamic oxidative air atmosphere in non-isothermal conditions at a heating rate $\beta=10^{\circ} \mathrm{C} \cdot \mathrm{min}^{-1}$, using a Perkin-Elmer DIAMOND instrument. Samples of approximately $8 \mathrm{mg}$ mass were directly weighted into open aluminum crucibles and subjected to thermal stress by increasing the temperature from ambient up to approximately $500{ }^{\circ} \mathrm{C}$. 
All the instrumental investigations were carried out in duplicate for each sample, and the results were practically identical.

\section{Results and Discussions}

As stated before, two investigational instrumental tools were chosen for the compatibility evaluation of TCR with the selected excipients in ambient conditions and under thermal stress, namely UATR-FTIR spectroscopy and thermoanalytical investigations.

\section{UATR-FTIR Study}

To evaluate the possible interactions that may occur between the pure pharmaceutical substance TCR and each of the selected excipients, the UATR-FTIR spectroscopic method was employed. The obtained spectrum for each binary mixture presented in Figure 2 was compared to the ones recorded for the pure compounds.

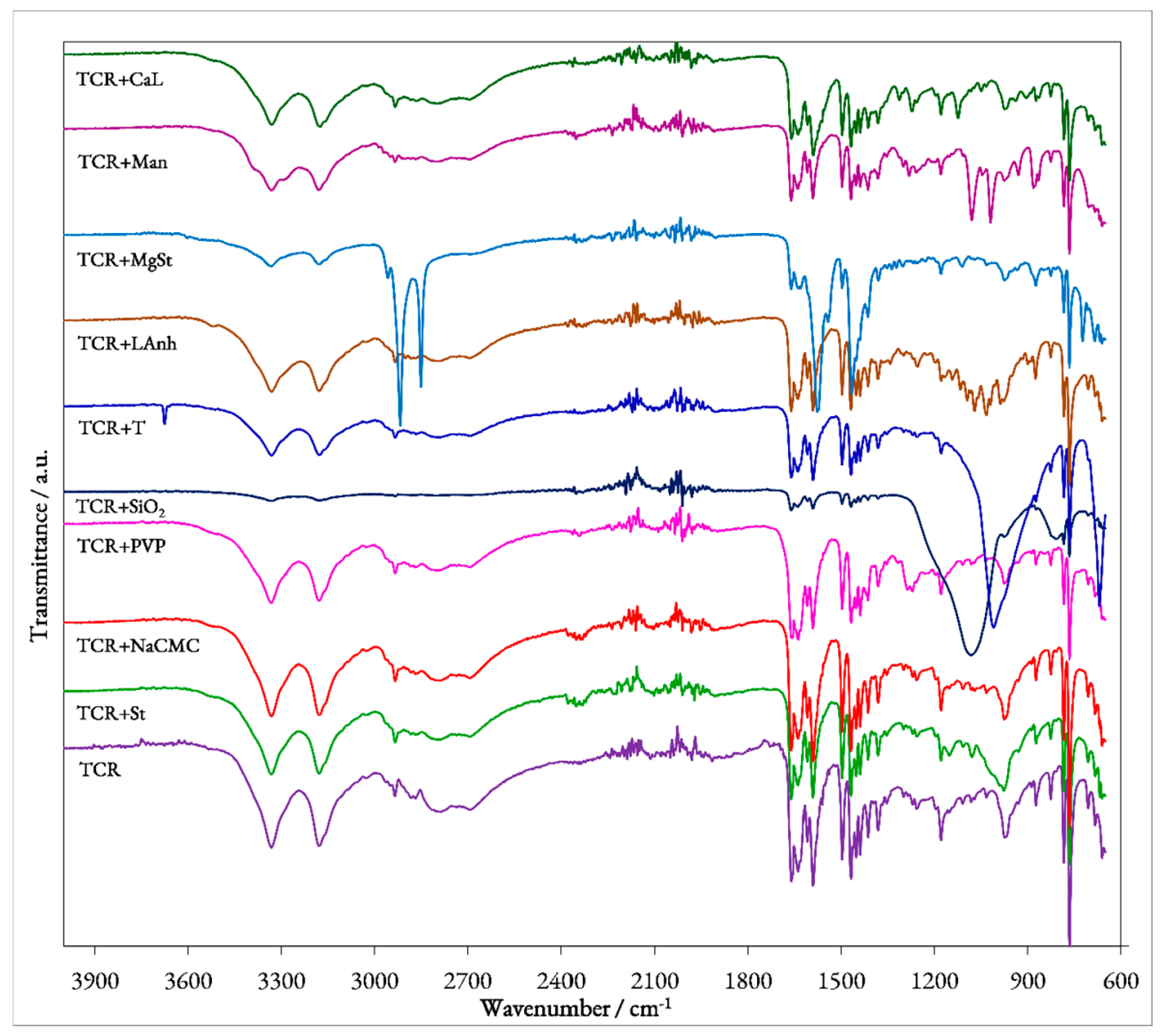

Figure 2. UATR-FTIR spectra of pure TCR and binary mixtures with excipients.

TCR's UATR-FTIR spectrum (Figure 2) reveals a series of bands, whose spectral position can be used to assess the identity and purity of the API. The obtained results are in agreement with data found in the literature, the most important observed spectral bands being easily correlated with the vibrations of TCR's characteristic functional moieties [I4,I8]. As such, the presence of the protonated primary amine 
group can be correlated with several bands, namely the ones seen at 3336 and $3180 \mathrm{~cm}^{-1}$ (determined by the asymmetric and symmetric stretching vibrations of the $\mathrm{N}-\mathrm{H}$ bond), at $166 \mathrm{I} \mathrm{cm}^{-1}$ (associated with the bending-scissoring-vibration of the $\mathrm{N}-\mathrm{H}$ bond) and at $1179 \mathrm{~cm}^{-1}$ (due to the stretching vibration of the $\mathrm{C}-\mathrm{N}$ bond). The observed bands can be found at higher frequencies (lower wavenumbers) in comparison with those usually observed for primary amine moieties, since in TCR's structure, the $-\mathrm{NH}_{2}$ group is linked to the aromatic pyridine ring. Since the compound is formulated as a hydrated hydrochloride, the presence of the crystallization water determines the presence of a broad band in the $3450-3050 \mathrm{~cm}^{-1}$ spectral range due to the stretching vibration of the $\mathrm{O}-\mathrm{H}$ bond. However, the two characteristic bands associated with the stretching vibration of the $\mathrm{N}-\mathrm{H}$ bonds from the primary amino group overlap with the $\mathrm{O}-\mathrm{H}$ band, making its observation difficult. The bands observed at $\mathrm{I} 59 \mathrm{I}$ and $1497 \mathrm{~cm}^{-1}$ can most likely be associated with the stretching vibrations of the $\mathrm{C}=\mathrm{C}$ and $\mathrm{C}=\mathrm{N}$ bonds present in the structure of the pyridine ring. The bending vibration of the $\mathrm{C}-\mathrm{H}$ bond from the same moiety determines the spectral presence of the low-intensity bands seen at IIIO and $1082 \mathrm{~cm}^{-1}$. Between 2960 and $2860 \mathrm{~cm}^{-1}$, a few bands with relatively low intensities can be observed, with peaks at 2935 and $2884 \mathrm{~cm}^{-1}$ that can be associated with the asymmetric and symmetric stretching vibrations of the $\mathrm{C}-\mathrm{H}$ bond from both aromatic and cyclohexane rings. The presence of the aromatic ring, namely of its $\mathrm{C}=\mathrm{C}$ bonds, in the structure of TCR, can be further confirmed by the series of bands observed in the $1600-1400 \mathrm{~cm}^{-1}$, with these overlapping the previously detailed stretching vibrations of the pyridine ring. In the $1000-700 \mathrm{~cm}^{-1}$ spectral range, a few bands can also be observed, the most intense ones being revealed at $976,873,823,782,762$ and $705 \mathrm{~cm}^{-1}$. In this region, multiple out-of-plane bending vibrations occur. As such, the observed overlaid bands can be associated with the vibrations of the $\mathrm{C}-\mathrm{H}$ aromatic bond, of pyridine's $\mathrm{C}-\mathrm{H}$ bond, of the wagging and twisting of the $-\mathrm{NH}_{2}$ moiety as well as the wagging of the $\mathrm{N}-\mathrm{H}$ bond. However, the most intense band, the one seen at $762 \mathrm{~cm}^{-1}$ represents, according to the literature [I4], the characteristic spectral band of TCR, a consequence of the presence of the aminopyridine moiety.

Regarding the FTIR spectra obtained for each prepared binary mixture, by analyzing the data presented in Table I, several preliminary observations can be made regarding the solid-state compatibility of TCR with each pharmaceutical excipient.

Table 1. UATR-FTIR data obtained for pure TCR and each binary mixture.

\begin{tabular}{|c|c|}
\hline Sample & Characteristic UATR-FTIR Bands/cm ${ }^{-1}$ \\
\hline TCR & $\begin{array}{l}3336 ; 3180 ; 2935 ; 2884 ; \text { I66I; I59I; I497; I469; I452; I438; I4I4; 1382; II79; IIIO; IO82; I032; 976; 873; 823; 782; } \\
764 ; 705\end{array}$ \\
\hline $\mathrm{TCR}+\mathrm{St}$ & 3330; 3177; 2932; 288I; I660; I590; I497; I468; I452; 1438; I413; 1381; II78; IIO8; I072; 976; 873; 824; 783; $765 ; 705$ \\
\hline $\mathrm{TCR}+\mathrm{NaCMC}$ & $\begin{array}{l}3330 ; 3177 ; 2933 ; 2880 ; 1660 ; 1590 ; 1497 ; 1468 ; 1452 ; 1439 ; \text { I413; 1380; I179; IIO8; 1079; 1030; 974; 873; 824; } \\
783 ; 765 ; 705\end{array}$ \\
\hline $\mathrm{TCR}+\mathrm{PVP}$ & $\begin{array}{l}\text { 333I; 3177; 2932; 288I; I656; I59I; I497; I468; I45I; I438; I4I4; I38I; II78; IIO8; I08I; 1036; 976; 873; 824; } \\
782 ; 765 ; 705\end{array}$ \\
\hline $\mathrm{TCR}+\mathrm{SiO}_{2}$ & $3327 ; 3175 ; 2932 ;$ I660; I591; I497; I468; I45I; I438; I4I3; I38I; II78; I079; 973; 807; 783; 765; 704 \\
\hline $\mathrm{TCR}+\mathrm{T}$ & $3676 ; 3327 ; 3176 ; 2932 ; 2869 ; 1660 ; 1590 ; 1497 ; 1468 ; 1465 ;$ I438; I413; I381; I179; 1009; 887; 824; $782 ; 765 ; 669$ \\
\hline TCR + LAnh & $\begin{array}{l}3330 ; 3178 ; 2933 ; 2898 ; 1660 ; 1591 ; 1497 ; 1468 ; 1452 ; \text { I438; I4I3; I38I; I253; II78; II42; III6; IO94; IO70; I032; IOI8; } \\
987 ; 898 ; 874 ; 826 ; 783 ; 765 ; 705\end{array}$ \\
\hline $\mathrm{TCR}+\mathrm{MgSt}$ & 3330; 3179; 2956; 2916; 2850; I66I; I577; I497; I465; I4I4; I380; II78; I109; 1031; 974; 873; 825; 783; 765; $723 ; 683$ \\
\hline $\mathrm{TCR}+\mathrm{Man}$ & $\begin{array}{l}3330 ; 3290_{\text {sh }} ; 3178 ; 2933 ; 2882 ; 166 \text { I I59I; I497; I468; I452; I438; I4I3; I38I; I28I; II79; 1079; IOI9; 974; 929; 88I; } \\
825 ; 783 ; 765 ; 703\end{array}$ \\
\hline $\mathrm{TCR}+\mathrm{CaL}$ & $\begin{array}{l}\text { 3331; 3179; 2933; } 2882 ; \text { I660; I589; I497; I486; I45I; I438; I4I3; I38I; I272; II79; II23; IO48; 972; 937; 903; 872; } \\
826 ; 782 ; 765 ; 704\end{array}$ \\
\hline
\end{tabular}


Therefore, it can be observed that for the mixtures TCR + St, TCR + NaCMC, TCR + NaCMC and TCR + PVP, the FTIR-obtained spectra are almost identical to the one presented by pure TCR, indicating that for these mixtures, no interactions occur in solid state and the pharmaceutical substance is compatible with these excipients. For the mixture $\mathrm{TCR}+\mathrm{SiO}_{2}$, the overall shape of the FTIR spectrum changes, because of the chemical structure of the excipient. The stretching vibration of the $\mathrm{Si}-\mathrm{O}$ bond found in $\mathrm{SiO}_{2}$ determines the appearance of a wide, very intense band in the spectrum of the mixture (seen at $1079 \mathrm{~cm}^{-1}$ ) that determines two overall changes. First, all of TCR's bands usually found in the $1300-900 \mathrm{~cm}^{-1} \mathrm{can}$ no longer be observed because of the width of the $\mathrm{Si}-\mathrm{O}$ band. Second, because of the high intensity of this spectral band, the remaining peaks that could be associated with the vibrations of TCR's bonds are almost unobservable due to their low intensity. A similar situation is encountered for the TCR + T mixture, since the excipient, talc, contains in its structure the same $\mathrm{Si}-\mathrm{O}$ bond whose vibration can be associated with the wide, intense band seen at $1009 \mathrm{~cm}^{-1}$. In the case of this mixture however, an additional peak can also be observed at $3676 \mathrm{~cm}^{-1}$ that can be associated, according to the literature, to the vibration of the hydroxyl ions in proximity to the three magnesium ions found in the structure of $\mathrm{T}[19,2 \mathrm{O}]$. As for the mixtures TCR + LAnh, TCR + MgSt, TCR + Man and TCR + CaL, although most of TCR's bands are present on the spectrum of each mixture, the overall aspect of the spectra is slightly different, suggesting possible interactions that occur between the components under ambient conditions. However, a clear confirmation of the occurring interactions can be done solely under thermal stress.

\section{Thermal Stress Study}

In order to get a clear view of the interactions that took place between TCR and each excipient during thermal stress, thermoanalytical investigations were carried out. As seen in Figure 3, TG/DTG/HF data were recorded for pure TCR (a), and all other nine samples, as follows: TCR $+\mathrm{St}(\mathbf{b}), \mathrm{TCR}+\mathrm{NaCMC}(\mathbf{c})$, $\mathrm{TCR}+\operatorname{PVP}(\mathbf{d}), \mathrm{TCR}+\mathrm{SiO}_{2}(\mathbf{e}), \mathrm{TCR}+\mathrm{T}(\mathbf{f}), \mathrm{TCR}+\mathrm{LAnh}(\mathrm{g}), \mathrm{TCR}+\operatorname{MgSt}(\mathbf{h}), \mathrm{TCR}+\mathrm{Man}(\mathbf{i})$ and $\mathrm{TCR}+\mathrm{CaL}(\mathbf{j})$, respectively.

Initially, the thermal stability of TCR was investigated. During thermal treatment from ambient temperature up to $500{ }^{\circ} \mathrm{C}$, the degradation of the pure compound shows a complex pathway of decomposition. Thermoanalytical data confirm that TCR is hydrated, since the first mass loss process takes place between 77 and $119{ }^{\circ} \mathrm{C}$, with a mass loss $\Delta m=7.17 \%$, corresponding to one mol of water per mol of anhydrous TCR hydrochloride (so that the value of $x$ from Figure $\mathrm{I}$ is $x=\mathrm{I}$ ). This process of dehydration is also confirmed by a DTG process occurring in the same temperature range, with a peak at IIO ${ }^{\circ} \mathrm{C}$ and by an endothermic event seen on the HF curve between 76 and $\mathrm{I} 24{ }^{\circ} \mathrm{C}$, with a $\mathrm{HF}_{\text {peak }}$ at III ${ }^{\circ} \mathrm{C}$. After dehydration, the anhydrous salt TCR is thermally stable in the $119-216^{\circ} \mathrm{C}$ temperature range, which can be considered significant for an organic compound; an explanation for this good thermal stability in such a large temperature interval is attributed to the saline structure of the edifice, corroborated with the structure of TCR that presents only condensed rings and only one lateral functional moiety, the amino one. With the advance in thermal treatment, the decomposition pathway of TCR is complex, consisting of both elimination of salt coformer $\mathrm{HCl}$ and the oxidation and breakdown of the organic skeleton of the drug. Between 216 and 5 I0 ${ }^{\circ} \mathrm{C}$, the mass loss is continuous and considerable $(\Delta m=80.5 \%)$, so the final residual char consists only of I2.91\% from initial mass. The DTG curve reveals two main processes, between 216 and $319{ }^{\circ} \mathrm{C}\left(\mathrm{DTG}_{\text {peak }}\right.$ at $\left.297^{\circ} \mathrm{C}\right)$ and 319 and $510{ }^{\circ} \mathrm{C}\left(\mathrm{DTG}_{\text {peak }}\right.$ at $\left.332^{\circ} \mathrm{C}\right)$, respectively. The $\mathrm{HF}$ curve shows enchained thermal events, both exothermic and endothermic, associated with the $\mathrm{HCl}$ release, melting with decomposition of the free base TCR and thermooxidations, as follows: HF peaks at 263, 273, 284, 299, 322, 334, 346 and $494^{\circ} \mathrm{C}$. According to the literature data, the melting with decomposition of TCR hydrochloride takes place between 543 to $547^{\circ} \mathrm{F}$ that corresponds to approximately 283 to $286^{\circ} \mathrm{C}$, with the reported data being in good agreement with our findings [2I]. 


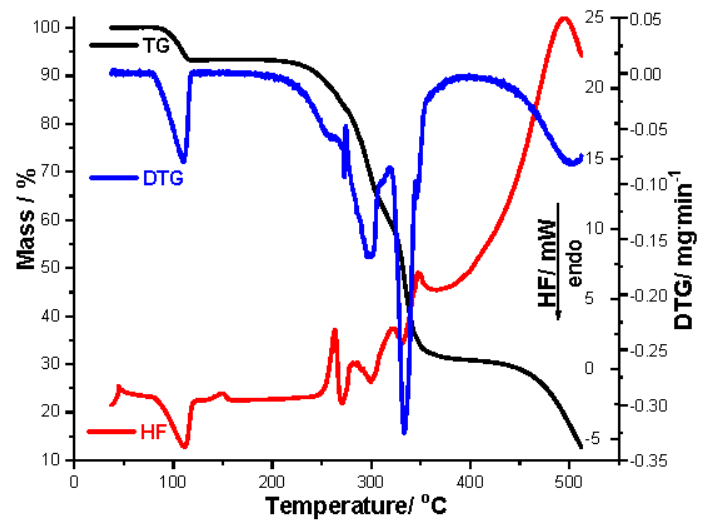

(a)

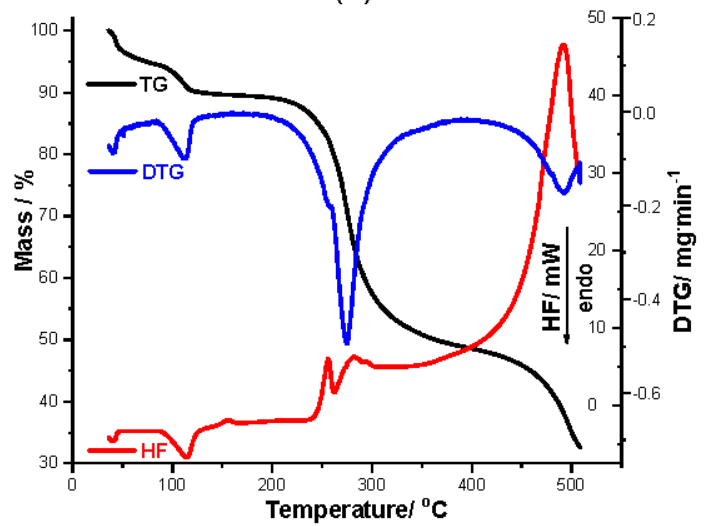

(c)

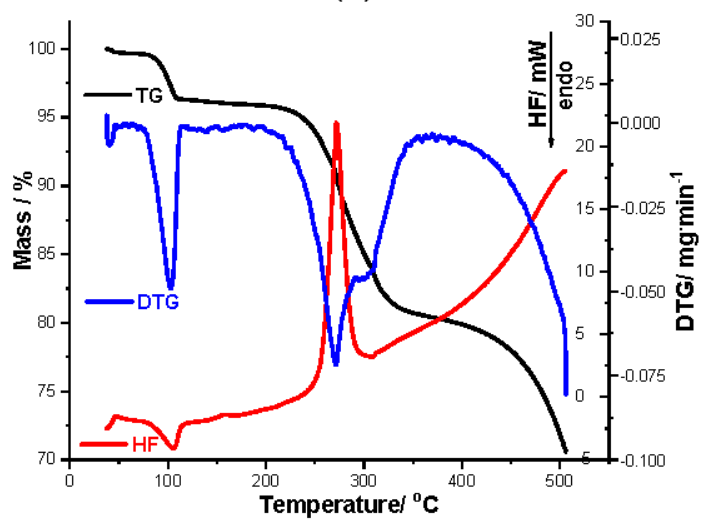

(e)

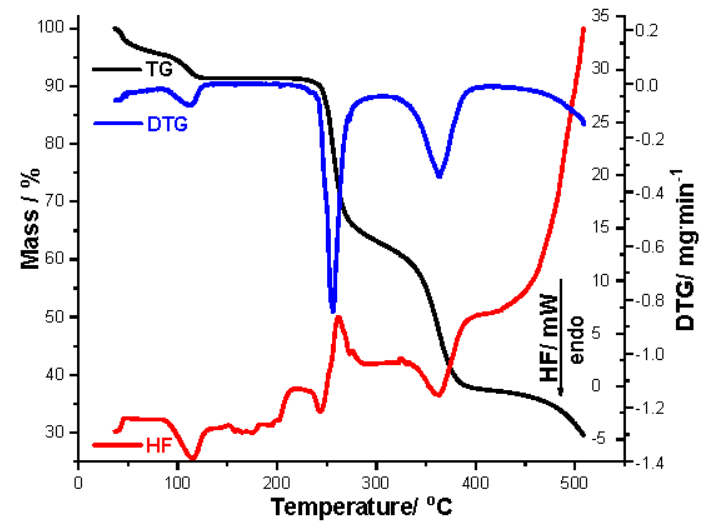

(b)

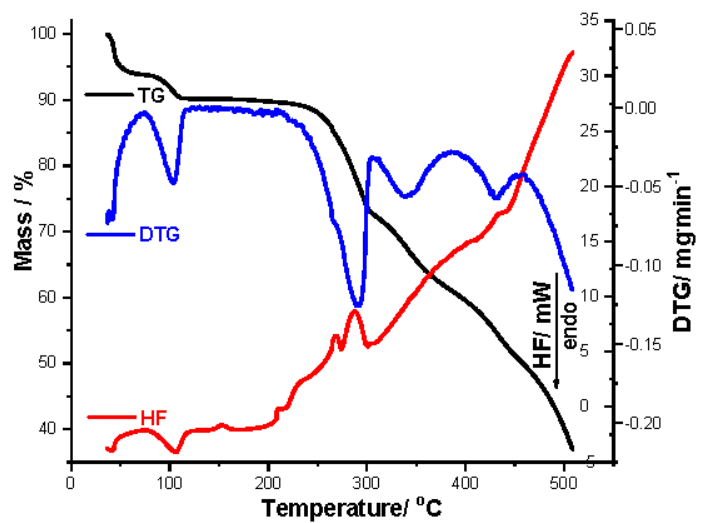

(d)

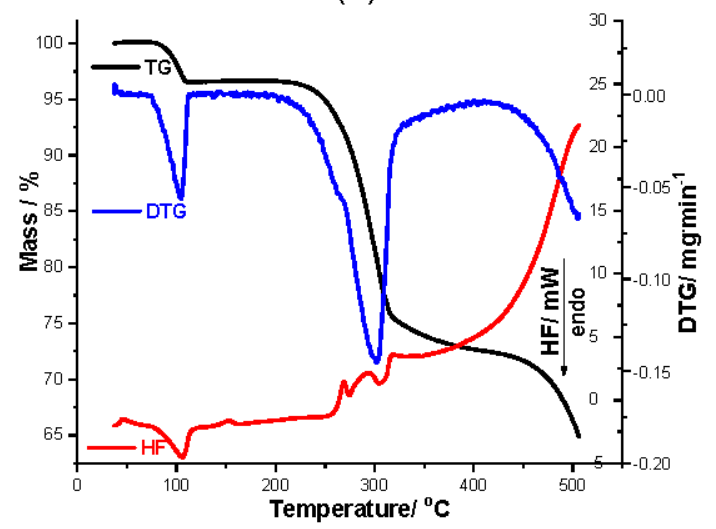

(f)

Figure 3. Cont. 


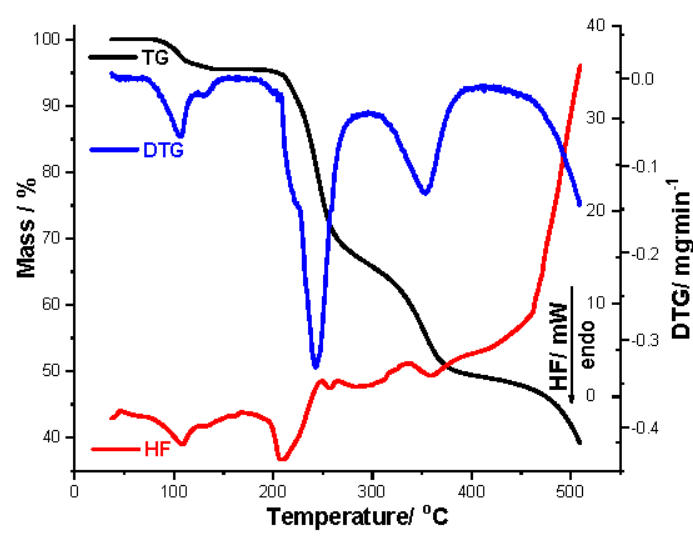

(g)

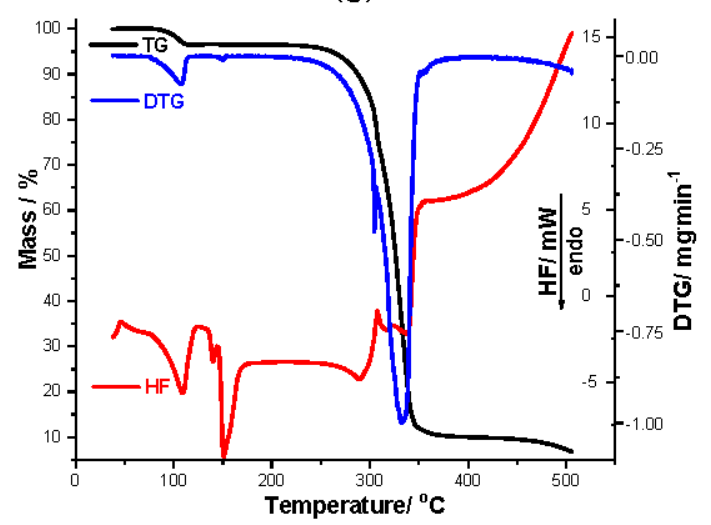

(i)

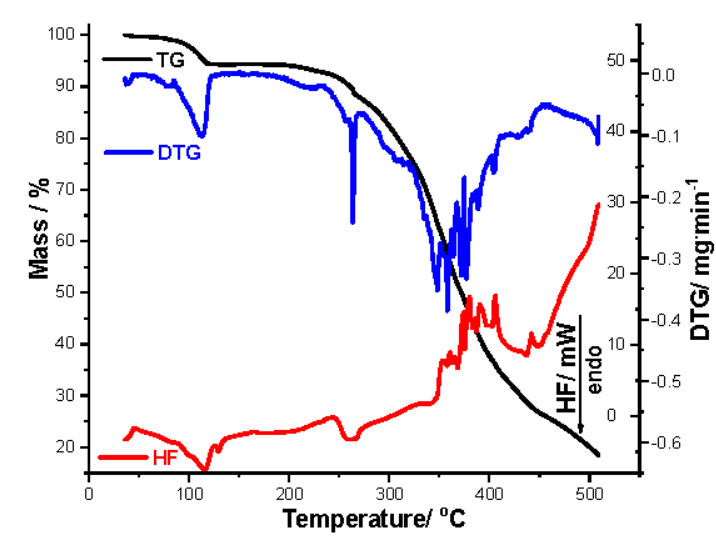

(h)

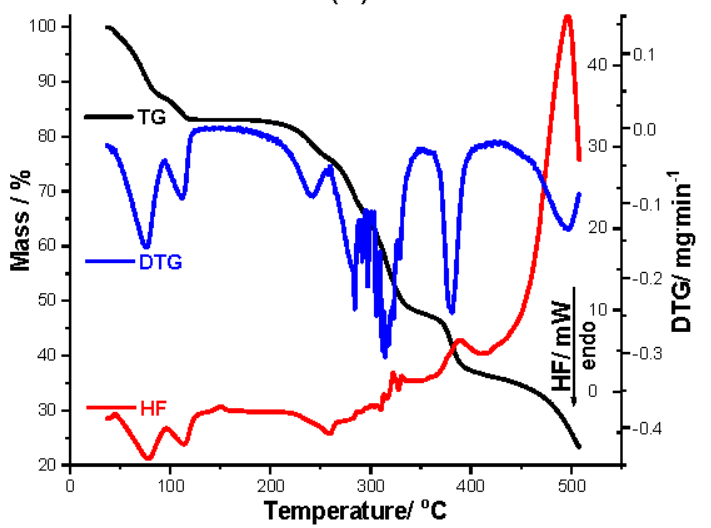

(j)

Figure 3. Thermogravimetry (TG) curves recorded for pure TCR (a) and TCR + excipient binary mixtures obtained in air at $\beta=10{ }^{\circ} \mathrm{C}$ min $^{-1}$ during thermolysis up to $500{ }^{\circ} \mathrm{C}$ as follows: $\mathrm{TCR}+\mathrm{St}(\mathbf{b}), \mathrm{TCR}+\mathrm{NaCMC}(\mathbf{c}), \mathrm{TCR}+\mathrm{PVP}(\mathbf{d})$, $\mathrm{TCR}+\mathrm{SiO}_{2}(\mathbf{e}), \mathrm{TCR}+\mathrm{T}(\mathbf{f}), \mathrm{TCR}+\mathrm{LAnh}(\mathbf{g}), \mathrm{TCR}+\operatorname{MgSt}(\mathbf{h}), \mathrm{TCR}+\mathrm{Man}(\mathbf{i})$ and TCR $+\mathrm{CaL}(\mathbf{j})$.

In the case of binary mixture $\mathrm{TCR}+\mathrm{St}$, the decomposition pathway is more complex, due to the composition of the excipient, including its water content. The dehydration of this binary mixture takes place between ambient temperature and $129^{\circ} \mathrm{C}$, with a mass loss $\Delta m=8.54 \%$, and the corresponding DTG process occurs between 85 and $126^{\circ} \mathrm{C}$ with a DTG ${ }_{\text {peak }}$ at $\mathrm{II}_{2}{ }^{\circ} \mathrm{C}$. The $\mathrm{HF}$ curve shows the endothermic dehydration between 84 and $129^{\circ} \mathrm{C}$, with a $\mathrm{HF}_{\text {peak }}$ at $114{ }^{\circ} \mathrm{C}$. Later on, the mixture is stable in the $129-226{ }^{\circ} \mathrm{C}$ temperature range, when the decomposition begins. Between 226 and $510{ }^{\circ} \mathrm{C}$, the partial mass loss of $\Delta m=6 \mathrm{I} .6 \mathrm{I} \%$ is due to two main processes revealed by both DTG and HF curves, as follows: $226-304{ }^{\circ} \mathrm{C}\left(\mathrm{DTG}_{\text {peak }}\right.$ at $257^{\circ} \mathrm{C}, \mathrm{HF}_{\text {peak }}$ at $260{ }^{\circ} \mathrm{C}$-exothermic) and $304-510{ }^{\circ} \mathrm{C}\left(\mathrm{DTG}_{\text {peak }}\right.$ at $363{ }^{\circ} \mathrm{C}, \mathrm{HF}_{\text {peak }}$ at $363{ }^{\circ} \mathrm{C}$-endothermic). As can be seen, the HF curve shows several thermal events between 130 and $270{ }^{\circ} \mathrm{C}$, similar to the profile observed for pure TCR, but attenuated in comparison to this, due to the fact that, in the binary mixture, the amount of TCR is $50 \%$, reported to the mass of the sample. However, this profile is a clear indication that the drug is compatible with St even under thermal stress.

The thermal investigations carried out for the binary mixture TCR $+\mathrm{NaCMC}$ reveal the dehydration process to mainly be in the same temperature range as previously observed, up to $138^{\circ} \mathrm{C}$, as shown by all thermoanalytical curves. At $138^{\circ} \mathrm{C}$, the mass loss is $\Delta m=10.17 \%$, and the process is highlighted by the DTG peak seen at $\mathrm{II}_{3}{ }^{\circ} \mathrm{C}$ and $\mathrm{HF}$ peak observed at $\mathrm{II}_{4}{ }^{\circ} \mathrm{C}$. The binary mixture is stable as anhydrous system between $\mathrm{I}_{3} 8$ and $\mathrm{I} 89^{\circ} \mathrm{C}$, followed by a rapid mass loss up to $5 \mathrm{IO}{ }^{\circ} \mathrm{C}(\Delta m=57.26 \%)$. The DTG curve reveals 
two well-defined events, with peaks at 275 and $49 \mathrm{I}{ }^{\circ} \mathrm{C}$, accompanied by three peaks in $\mathrm{HF}$ curve: $256{ }^{\circ} \mathrm{C}$ (exothermic), $263{ }^{\circ} \mathrm{C}$ (endothermic), $284{ }^{\circ} \mathrm{C}$ (exothermic), as well as the main degradative event at $493{ }^{\circ} \mathrm{C}$, this being highly exothermic in nature. For this binary heterogenous mixture, there are no indications of thermally induced interactions between the components.

When subjected to thermal stress, the mixture TCR + PVP loses water between 25 and $116{ }^{\circ} \mathrm{C}$, with the mass loss being $\Delta m=9.78 \%$. The HF curve reveals a two-step dehydration, the first occurring in the $25-73{ }^{\circ} \mathrm{C}$ range $\left(\mathrm{DTG}_{\text {peak }}\right.$ at $4 \mathrm{I}^{\circ} \mathrm{C}$, endothermic $\mathrm{HF}_{\text {peak }}$ at $\left.42^{\circ} \mathrm{C}\right)$ can be associated with the release of superficially adsorbed water, while the second is due to the dehydration of TCR $\left(73-116{ }^{\circ} \mathrm{C}\right.$ range, DTG peak at $105^{\circ} \mathrm{C}$, endothermic $\mathrm{HF}_{\text {peak }}$ at $\left.106{ }^{\circ} \mathrm{C}\right)$. The mixture is thermally stable in the $116-216{ }^{\circ} \mathrm{C}$ temperature range, very similar to pure TCR, suggesting that in this case, there is also compatibility between the components, even under thermal treatment. At higher temperatures, the decomposition profile is more complex, as revealed by the DTG curve and its peaks seen at 292,338 and $432{ }^{\circ} \mathrm{C}$. The HF profile reveals some endothermal and exothermal events, including the peaks that characterize TCR, suggesting the lack of interactions between the components.

The presence of $\mathrm{SiO}_{2}$ alongside TCR in the mixture determines a modification of the thermal behavior of the pharmaceutical compound, including the decomposition pathway. The dehydration of TCR occurs between ambient conditions and at $\mathrm{II}_{4}{ }^{\circ} \mathrm{C}$, as revealed by all three thermoanalytical curves: TG shows a mass loss $\Delta m=3.63 \%$, two DTG peaks are revealed at 39 and $\mathrm{IO}^{\circ}{ }^{\circ} \mathrm{C}$, respectively, and $\mathrm{HF}$ endothermic peaks can be seen at 40 and $\operatorname{10}{ }^{\circ} \mathrm{C}$, confirming the dehydration. The fact that the mass loss in this temperature range is half the value recorded for the pure TCR is explained by the composition of the mixture (consisting I:I mass TCR vs. excipient) and sustained by the fact that the excipient is anhydrous. The attenuation of the observed thermal events on the HF curve in the range $114-233^{\circ} \mathrm{C}$ is due to the intense exothermic event seen between 233 and $310^{\circ} \mathrm{C}$ (peak at $27 \mathrm{I}^{\circ} \mathrm{C}$ ), that can be attributed tentatively to a catalytic effect of the inorganic excipient over degradation of TCR. For this binary mixture, a thermally induced interaction is plausible, but the corroboration of the results with UATR-FTIR spectroscopy suggests that interactions do not occur under ambient conditions.

Talc is compatible with TCR even under thermal stress. A similar thermal profile is observed for this binary mixture when compared to the pure therapeutic agent, this fact being plausible since the thermal inertia of this excipient is well known. The dehydration step occurring up to $\mathrm{III}^{\circ}{ }^{\circ} \mathrm{C}(\Delta m=3.44 \%)$ confirms that the excipient is anhydrous, so that the water release is solely due to the dehydration of TCR. The HF curve reveals the characteristic peak from $106^{\circ} \mathrm{C}$, as well as the other thermal events that take place between 200 and $350^{\circ} \mathrm{C}$. The final char has a residual mass of $64.96 \%$, considerably higher than the ones containing organic excipients, that are not as thermally inert as talc.

The spectroscopic results that suggested an incompatibility between TCR and LAnh were also confirmed by thermal analysis. Even if the dehydration step is similar for the API in binary mixture, as in the one seen for pure TCR $\left(\mathrm{HF}_{\text {peak }}\right.$ at $\left.107{ }^{\circ} \mathrm{C}\right)$, the HF profile is way more complex, consisting of the overlapping of the degradative processes of the excipient with the ones of TCR, but with disappearance of the thermal event associated with the melting of the pure pharmaceutical agent. The corroboration of the spectral results with the ones revealed during thermal analysis lead to a clear indication that interactions between TCR and this excipient occur even under ambient conditions. The numerous events suggested by the HF curve at high temperatures may be explained by the condensation of the free amino group of TCR with reactive species formed by dehydration of lactose, via Schiff-type and Maillard-type reactions. 
Magnesium stearate $(\mathrm{MgSt})$ is also incompatible with TCR, albeit by an unknown mechanism. However, acid-base reactions may occur between TCR and the impurities from this excipient under thermal stress. Dehydration of this binary sample takes place up to $124^{\circ} \mathrm{C}$, with $\Delta m=5.72 \%$, a DTG peak seen at $114{ }^{\circ} \mathrm{C}$ and a corresponding $\mathrm{HF}_{\text {peak }}$ observed at II $8^{\circ} \mathrm{C}$. The melting of TCR is no longer visible on the $\mathrm{HF}$ curve, suggesting the presence of interactions occurring between the components. The thermal results and the UATR-FTIR data are in concordance, with interactions being suspected with this excipient even under ambient conditions.

Mannitol is incompatible with TCR, both under ambient conditions and thermal stress. The obtained thermoanalytical profile of this binary mixture was similar to the one previously presented for lactose. Following the dehydration step of TCR, the sugar alcohol Man will interact, by Maillard-type condensation reactions, with the drug, leading to severe incompatibilities.

The thermal behavior of TCR $+\mathrm{CaL}$ reveals a considerable mass loss up to $124{ }^{\circ} \mathrm{C}$, due to the release of water molecules both from the excipient and the pure pharmaceutical agent $(\Delta m=16.90 \%)$. The water elimination is well-individualized on the HF curve, indicated by two consecutive processes that take place between 44 and $97^{\circ} \mathrm{C}$ (peak at $77^{\circ} \mathrm{C}$ ) and 97 and $124^{\circ} \mathrm{C}$ (peak at $115^{\circ} \mathrm{C}$ ), respectively. The melting of TCR is not observable on the HF curve, suggesting a thermally induced interaction.

\section{Conclusions}

In this paper, the compatibility between the AChE agent tacrine and nine different pharmaceutical excipients, namely calcium lactate, mannitol, magnesium stearate, anhydrous lactose, talc, fumed silica, polyvinylpyrrolidone $\mathrm{K}_{3} \mathrm{O}$, sodium carboxymethyl cellulose and starch, was investigated using UATR-FTIR spectroscopy and thermal analysis. The corroboration of the data obtained via the two complementary methods confirmed the incompatibility of this drug with glucide-type excipients (anhydrous lactose and mannitol) as well as with salts (magnesium stearate and calcium lactate). Even if the spectroscopic analysis does not indicate a possible incompatibility between tacrine and fumed silica under ambient conditions, thermal analysis revealed that interactions occur under heating. Following the results, the above-mentioned excipients that interact with tacrine should be avoided in the development of solid formulations containing this pharmaceutical active ingredient, while starch, sodium carboxymethyl cellulose, polyvinylpyrrolidone $\mathrm{K}_{3} \mathrm{O}$ and talc can be used, since they are compatible with tacrine under ambient conditions and as well under thermal stress.

Author Contributions: Conceptualization, I.L. and D.C.; Methodology, A.L.; Software, D.C. and A.L.; Validation, G.V. and A.L.; Formal Analysis and Investigation, G.V. and T.V.; Resources and Funding Acquisition, A.L.; Data Curation, A.L. and T.V.; Writing-Original Draft Preparation, I.L. and D.C.; Writing-Review and Editing, A.L., G.V. and T.V. All authors have read and agreed to the published version of the manuscript.

Funding: This research was funded by UEFISCDI, PN-II-RU-TE-20I4-4-05I5 project (NEUROPHARM) to Adriana Ledeți, Ionuț Ledeți, Denisa Circioban.

Conflicts of Interest: The authors declare no conflict of interest. The funders had no role in the design of the study; in the collection, analyses, or interpretation of data; in the writing of the manuscript, or in the decision to publish the results.

\section{References}

I. World Health Organization. Dementia. Available online: https://www.who.int/news-room/fact-sheets/detail/ dementia (accessed on io September 2020).

2. De la Torre, J.C. Alzheimer's Turning Point; Springer International Publishing: Cham, Switzerland, 2or6; pp. 4-19. 
3. Sharma, K. Cholinesterase inhibitors as Alzheimer's therapeutics (Review). Mol. Med. Rep. 2019, 20, I479-I487. [CrossRef] [PubMed]

4. Jarrott, B. Tacrine: In vivo veritas. Pharmacol. Res. 2017, 116, 29-3I. [CrossRef] [PubMed]

5. Freeman, S.E.; Dawson, R.M. Tacrine: A pharmacological review. Prog. Neurobiol. 1991, 36, $257-277$. [CrossRef]

6. DrugBank Online DBoo382 Tacrine. Available online: https://go.drugbank.com/drugs/DBoo382 (accessed on Io September 2020).

7. Tacrine Hydrochloride. Available online: https://www.chemicalbook.com/ChemicalProductProperty_US_ CB540266r.aspx (accessed on io September 2020).

8. Madden, S.; Spaldin, V.; Park, B.K. Clinical Pharmacokinetics of Tacrine. Clin. Pharmacokinet. 1995, 28, 449-457. [CrossRef] [PubMed]

9. Tsopelas, N.D.; Marin, D.B. Cholinergic Treatments of Alzheimer's Disease. Funct. Neurobiol. Aging 2001, 1, $475-486$.

Io. Anand, P.; Singh, B. A review on cholinesterase inhibitors for Alzheimer's disease. Arch. Pharm. Res. 2013, 36, 375-399. [CrossRef] [PubMed]

II. Hassani, S.; Laouini, A.; Fessi, H.; Charcosset, C. Preparation of chitosan-TPP nanoparticles using microengineered membranes-Effect of parameters and encapsulation of tacrine. Colloids Surfaces $A$ Physicochem. Eng. Asp. 2015, 482, 34-43. [CrossRef]

I2. Patel, N.; Jain, S.; Madan, P.; Lin, S. Influence of electronic and formulation variables on transdermal iontophoresis of tacrine hydrochloride. Pharm. Dev. Technol. 2015, 20, 442-457. [CrossRef] [PubMed]

13. Patel, N.; Jain, S.; Lin, S. Transdermal iontophoretic delivery of tacrine hydrochloride: Correlation between in vitro permeation and in vivo performance in rats. Int. J. Pharm. 2016, 513, 393-403. [CrossRef] [PubMed]

I4. Luppi, B.; Bigucci, F.; Corace, G.; Delucca, A.; Cerchiara, T.; Sorrenti, M.; Catenacci, L.; Di Pietra, A.M.; Zecchi, V. Albumin nanoparticles carrying cyclodextrins for nasal delivery of the anti-Alzheimer drug tacrine. Eur. J. Pharm. Sci. 2011, 44, 559-565. [CrossRef] [PubMed]

15. de Lima Gomes, E.C.; Ercole de Carvalho, I.; Fialho, S.L.; Barbosa, J.; Yoshida, M.I.; da Silva Cunha Júnior, A. Mixing method influence on compatibility and polymorphism studies by DSC and statistical analysis: Application to tenofovir disoproxil fumarate. J. Therm. Anal. Calorim. 2018, 131, 2123-2128. [CrossRef]

16. Aleeva, G.N.; Zhuravleva, M.V.; Khafiz'Yanova, R.K. The role of excipients in determining the pharmaceutical and therapeutic properties of medicinal agents (Review). Pharm. Chem. J. 2009, 43, 230-234. [CrossRef]

17. Chadha, R.; Bhandari, S. Drug-excipient compatibility screening-Role of thermoanalytical and spectroscopic techniques. J. Pharm. Biomed. Anal. 2014, 87, 82-97. [CrossRef] [PubMed]

I8. Igartúa, D.E.; Martinez, C.S.; del V. Alonso, S.; Prieto, M.J. Combined Therapy for Alzheimer's Disease: Tacrine and PAMAM Dendrimers Co-Administration Reduces the Side Effects of the Drug without Modifying its Activity. AAPS PharmSciTech 2020, 21, I-I4. [CrossRef] [PubMed]

19. Ferrage, E.; Martin, F.; Petit, S.; Pejo-soucaille, S.; Micoud, P.; Fourty, G.; Ferret, J.; Salvi, S.; De Parseval, P.; Fortune, J.P. Evaluation of talc morphology using FTIR and H/D substitution. Clay Miner. 2003, 38, I4I-I5O. [CrossRef]

20. Wilkins, R.W.T.; Ito, J. Infrared spectra of some synthetic talcs. Am. Mineral. 1967, 52, I649-166I.

21. National Center for Biotechnology Information PubChem Compound Summary for CID 2723754, Tacrine Hydrochloride. Available online: https://pubchem.ncbi.nlm.nih.gov/compound/Tacrine-hydrochloride (accessed on 5 August 2020).

() 2020 Copyright by the authors. Licensed as an open access article using a CC BY 4.0 license.

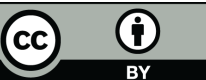

